\title{
Comparison of child and adult vibrotactile thresholds
}

\author{
RONALD T. VERRILLO \\ Institute for Sensory Research, Syracuse University, Syracuse, New York 13210
}

\begin{abstract}
Vibrotactile detection thresholds were measured in two groups of six subjects each: a child group having a mean age of 10 years, and an adult group having a mean age of 21 years. Measurements were made on the thenar eminence at frequencies between 25 and $700 \mathrm{~Hz}$ using four contactor sizes ranging from .005 to $2.9 \mathrm{~cm}^{2}$. Results show that children are more sensitive than adults to sinusoidal vibrations at most frequencies and that spatial summation is a functional characteristic of children's skin. The results are consistent with a filter model of the Pacinian corpuscle.
\end{abstract}

A rather large body of literature has been published concerning the measurement of adult responses to vibrotactile stimuli. Many parameters of the physical stimulus have been investigated, including frequency of vibration (Békésy, 1939; Sherrick, 1953; Verrillo, 1962, 1963, 1966b), contactor size (Craig, 1966, 1968; Verrillo, 1963, 1966a), temporal variables (Verrillo, 1965, 1971a), and intensity (Stevens, 1959, 1968; Verrillo, 1970; Verrillo, Fraioli, \& Smith, 1969). This list comprises only the more salient features of the physical stimulus. The results of psychophysical experimentation, coupled with data reported from electrophysiological laboratories, led to the formulation of a duplex theory of cutaneous mechanoreception (Verrillo, 1968) which proposed that at least two mechanoreceptor systems could be distinguished in cutaneous tissue. One of the systems mediated predominantly high-frequency signals. This system has as its receptor end organ the Pacinian corpuscle. The other system, whose end organs are probably Meissner corpuscles and hair follicle endings, determines the psychophysical response at low frequencies.

The morphology and distribution of cutaneous receptors are known to undergo changes with age (Cauna, 1965). It is important to know if the changes in physical structure are accompanied by changes in the sensitivity to vibration. Such comparisons can lead to a better understanding of the developmental aspects of vibrotactile sensitivity as well as of the functional characteristics of cutaneous mechanoreceptors. Another, and perhaps more practical, reason for studying possible changes with age involves the use of skin as a substitute channel of communication for the blind and the profoundly deaf. Any practical system for utilizing the skin for communication purposes must be applicable to a younger population, since much of the training in the use of such systems usually commences prior to aduithood.

This research was supported by Grant NS-09940 from the National Institutes of Health, United States Department of Health, Education, and Welfare.
This study was designed to investigate the effects of sinusoidal frequency and the area of the contactor upon the detection thresholds of a group of six children. The results are compared to a group of six young adults. The comparison will be used in order to test predictions made from our knowledge of the structure and functional characteristics of the Pacinian corpuscle and the changes that occur in the receptor as a function of age.

\section{METHOD AND PROCEDURE}

Threshold determinations were made on a group of six children and six adults. There were three males and three females in each group. The children ranged in age from 8 to 12 years, with a mean age of 10 years. The adult group had a range of 18 to 23 years and mean age of 21 years. All measurements were made on the thenar eminence of the right hand using the Békésy (1939) tracking method. The subjects and the vibratory apparatus were located inside a booth which provided isolation from extraneous vibrations and noise. Narrow-band noise was delivered through earphones to mask the sound of the vibrator.

The output of a sine-wave generator was modulated by an electronic switch so that the signal was on for $1 \mathrm{sec}$ and off for 1 sec. A rise-decay time of $100 \mathrm{msec}$ was used to avoid switching transients. The signal was then passed through a tracking attenuator (Grason-Stadler, Model E3262A), whose output was controlled by the subject. After appropriate amplification, the signal was delivered to the vibrator.

Accurate measurement of the stimulus at the time of stimulation was accomplished by means of a center-hole accelerometer (Endevco 2221C) mounted directly on the moving element of the vibrator. The voltage output of the accelerometer was transformed to microns of peak displacement and then converted to decibels.

The vibrator (Goodmans 390A) was mounted on an adjustable platform under a rigid surface so that the contactor protruded through a hole in the surface. A series of adapting surrounds were used so that the gap between the contactor and the rigid surround was always $1.0 \mathrm{~mm}$, regardless of contactor size. The subject sat with right forearm and hand, palm down, resting comfortably on the rigid surface with the thenar eminence positioned over the contactor. Before each experimental session, the height of the contactor was carefully adjusted so that the contactor pressed into the skin approximately $1.0 \mathrm{~mm}$. This insured that the contactor did not lose contact with the skin during the sinusoidal oscillations.

Threshold measurements were determined at frequencies of $25,40,80,100,160,250,320$, and $640 \mathrm{~Hz}$, using contactor sizes of $.005, .05, .32$, and $2.9 \mathrm{~cm}^{2}$. The data reported are 
group medians of three measurements made for each subject and are expressed in decibels referred to 1.0 micron of peak displacement.

\section{RESULTS AND DISCUSSION}

Threshold displacement of the child and adult groups is compared in Figure 1, where median results obtained with two contactor sizes are plotted as a function of stimulus frequency. There were no differences between male and female thresholds in either group. Several important features are apparent in the data. First, the effect of stimulus frequency upon the vibrotactile threshold is strongly affected by the size of the contactor. The pronounced frequency effect, evidenced by the U-shaped curve, obtained with the large contactor is absent in the adult group and greatly reduced in the child group when the small contactor was used. The results shown for the adult group have been found previously in a number of studies (Gescheider, 1976; Verrillo, 1962, 1963, 1966b, c). The second feature to note is the discontinuity in the adult large-contactor curve that occurs at a frequency of about $40 \mathrm{~Hz}$. This effect was first observed by Békésy (1939) and later verified in a number of carefully controlled experiments (Gescheider, 1976; Verrillo, 1963, 1966a, b; and others). Both of these effects have been interpreted as indicating that the skin contains at least two mechanoreceptive systems: a system that integrates energy at threshold over time and space, and another that is not affected by temporal or spatial patterning (Verrillo, $1965,1966 \mathrm{c}, 1968)$. The system exhibiting properties of temporal and spatial summation was identified as the Pacinian corpuscle by psychophysical experiments (Verrillo, 1966c, d) and later confirmed by electrophysiological measurements (Talbot, Darian-Smith, Kornhuber, \& Mountcastle, 1968).

The results in Figure 2 show the effect of contactor area upon vibrotactile thresholds of the child group measured at five frequencies. It is again apparent that two response modes can be discriminated. At $25 \mathrm{~Hz}$ the size of the contactor has no apparent effect on the threshold. At frequencies greater than $40 \mathrm{~Hz}$ the sensitivity to vibration increases at the rate of about $3 \mathrm{~dB}$ for every doubling of contactor area. This indicates that the high-frequency system summates energy over space at threshold, whereas the low-frequency system does not. Spatial summation has been observed in a number of experiments using adult subjects (Craig, 1968; Gescheider, 1976; Verrillo, 1963, 1966a).

There are several rather obvious discrepancies between the adult and child groups. In Figure 1 the child results obtained with the large contactor do not contain a discontinuity at $40 \mathrm{~Hz}$, but rather describe a U-shaped function starting at $25 \mathrm{~Hz}$. The curve indicates a greater senstivity in the child group amounting to approximately $6 \mathrm{~dB}$ at frequencies below $200 \mathrm{~Hz}$. This result is consistent with what is known about the mechanical structure of the Pacinian corpuscle as well as the changes that the corpuscle undergoes with age.

The Pacinian corpuscle is a widely distributed receptor end organ found in cutaneous tissue, in the viscera, around joints and muscle tendons, in the interosseous membranes and periosteum, and often near arteries and nerve bundles. Its structure consists of a large, thickly myelinated axon whose terminal is surrounded by concentric, alternating layers of connective tissue (lamellae) and fluid. Cut in cross section, it has the appearance of an onion. Its general shape is oval in infants but changes in the adult to a more distorted configuration (see Figure 3).

A number of electrophysiological investigations have been made of the Pacinian corpuscle response to direct mechanical stimulation (Hubbard, 1958; Loewenstein \& Mendelson, 1965; Loewenstein \& Rathcamp, 1958). Based on these investigations, Loewenstein and Skalak (1966) have provided an

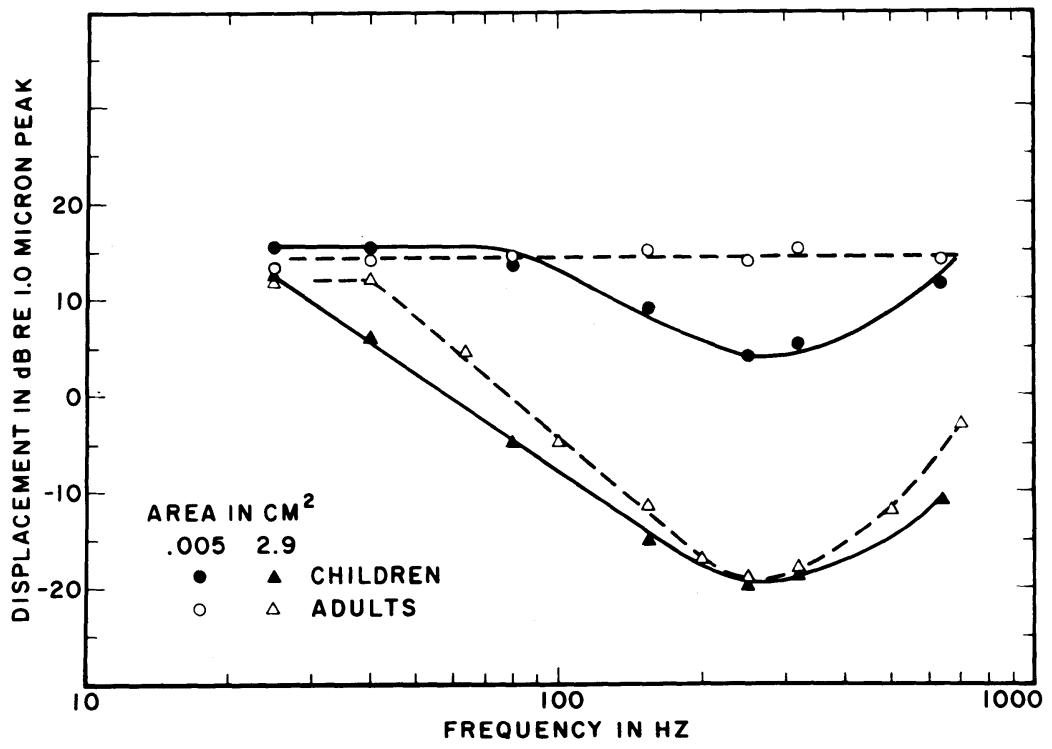

Figure 1. Comparison of vibrotactile thresholds in a group of children and a group of adults. The measurements were made on the thenar eminence using two contactor sizes: .005 and $2.9 \mathrm{~cm}^{2}$. Note that the adult curve obtained with the large contactor has a flat portion below $40 \mathrm{~Hz}$ and the child curve is U-shaped throughout. 


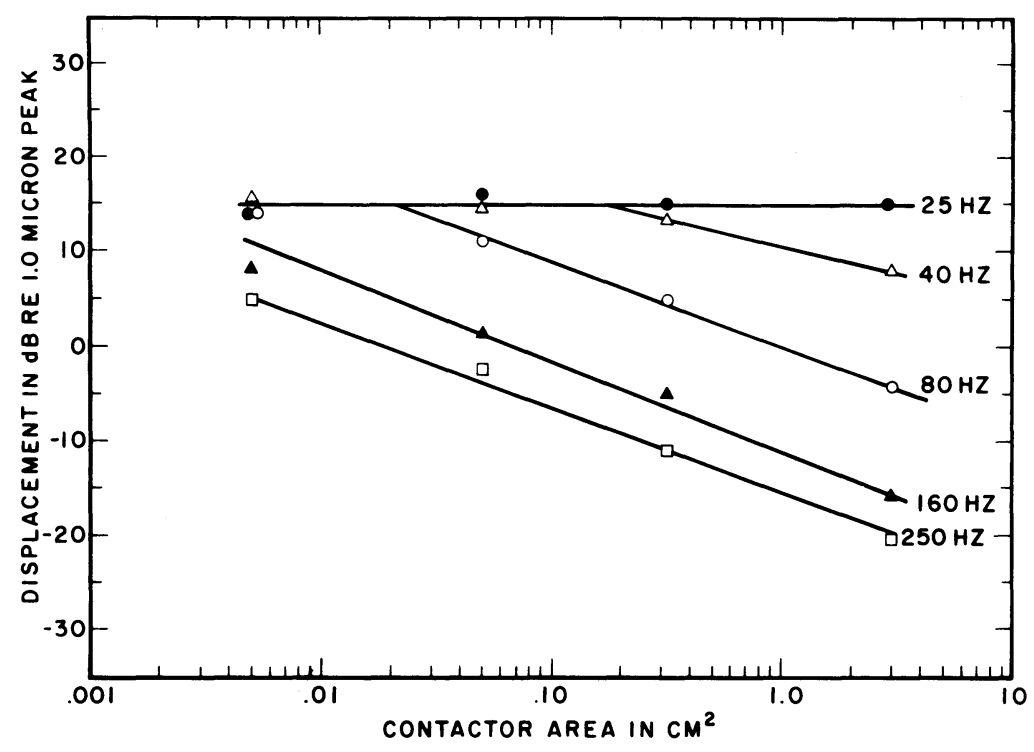

Figure 2. Vibrotactile thresholds of the child group plotted as a function of contactor area with frequency as the parameter. The slopes of the curves fall off at approximately $3 \mathrm{~dB}$ per doubling of contactor area, indicating complete summation of energy over space at high frequencies. Measurements made at $25 \mathrm{~Hz}$ show no spatial summation.

electromechanical analog model in which the corpuscular lamellae act as a mechanical high-pass filter for physical energy. The filter requires a critical velocity of the stimulus in order for the displacement energy to be transmitted to the inner core where the axon is located. The displacement velocities of low-frequency signals is not sufficient to activate the axon, since the energy is dissipated in the lamellae and fluid of the capsule. Higher frequencies are passed with varying degrees of efficiency. Modification of the Loewenstein and Skalak (1966) model to produce a band-pass filter could result in a filtering action to account in part for the U-shaped portion of the adult curve. At the low frequencies, the physiological threshold of the Pacinian corpuscle is higher than that of the non-Pacinian receptors. Thus, the threshold response in the flat portion of the curve may be considered the result of activity in the non-Pacinian receptor system.

The frequency function of the child group has no flattened portion in the low frequencies but is U-shaped throughout. In addition, the slope of the curve is less than that of the adult curve at both low and high frequencies. The slope in the low-frequency portion of the adult curve is $-12 \mathrm{~dB}$ per doubling of frequency and the comparable slope of the child curve is $-10 \mathrm{~dB}$. This effect was predictable from the structural changes in the Pacinian corpuscle that occur with age. Cauna (1965) has made a detailed study of age changes in cutaneous receptor end organs in samples of human skin, taken from more than 200 individuals ranging in age from birth to 93 years. He demonstrated that in the infant the corpuscle is small, regular in shape (oval), and has few lamellae. Throught the life of the individual, lamellae are added, the corpuscle increases in size and becomes distorted in shape.

The schematic drawing in Figure 3, redrawn from Cauna (1965, Figure 3), compares an infant corpuscle with that of a 49-year-old male. The change in shape as well as the increase in size can be seen clearly. The apposition of new lamellae around the periphery results in an approximate threefold increase in length and 6.25 times the cross-sectional area in the adult corpuscle. The effect of increasing the number of filter elements could quite reasonably result in the decreased sensitivity as well as the change in slope of the adult curve as compared to that of the child. The spatial summation shown in Figure 2 would not be affected by the geo-

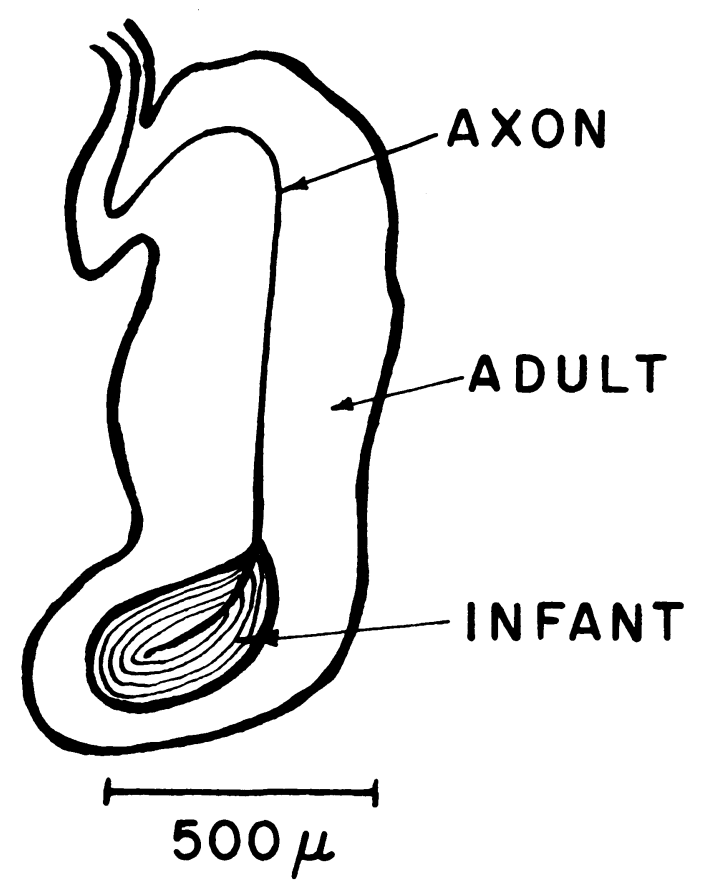

Figure 3. Schematic drawing comparing the size and geometric configuration of an infant and a 49-year-old male Pacinian corpuscle taken from the index finger. The concentric lamellae of the adult corpuscle have not been drawn. The increase in the number of lamellae and consequent increase in size of the adult corpuscle represents an approximate threefold greater length and 6.25 times greater cross-sectional area (redrawn from Cauna, 1965). 
metric configuration of the corpuscle. The child results are in agreement with those of an adult group reported in a previous investigation (Verrillo, 1966a).

The child results obtained with the small contactor (Figure 1) are similar to adult data measured at the fingertip (Verrillo, 1971b), in that both curves have a U-shaped portion at the middle frequencies. This is an expected result since the thenar eminence of the child and the adult fingertip have a higher density of corpuscles than the adult thenar eminence. The likelihood that the very small contactor will provide sufficient energy to excite a corpuscle within this population is thereby increased.

Although the child group was considerably more sensitive at most frequencies, the thresholds at $25 \mathrm{~Hz}$ and $250 \mathrm{~Hz}$ in both groups were virtually the same. This is an expected result, given the filter analog for the Pacinian corpuscle. It is unfortunate that measurements were not made at lower frequencies, since the Meissner corpuscle also undergoes structural and density changes with age (Cauna, 1965). This receptor is sensitive at the low frequencies and probably accounts for the flat portion of the adult curve, but there is no way of determining from these data how to project the curve at the lower end.

\section{SUMMARY AND CONCLUSIONS}

A comparison of vibrotactile thresholds measured on the thenar eminence of a group of children and adults shows distinct similarities and differences. When plotted as a function of stimulus frequency, the adult function is flat for frequencies below $40 \mathrm{~Hz}$ and U-shaped at higher frequencies. The curve obtained from the child group is U-shaped throughout the frequency range and the slopes of the limbs of the curve are less steep. These differences may be expected, considering the structure and functional characteristics of the Pacinian corpuscle and considering also the structural changes in the corpuscle that occur with age. The child data also show a reduction in threshold as a function of contactor size consistent with near perfect spatial summation of energy. The results agree with previous measurements made on an adult group.

The child group was considerably more sensitive than the adult group, especially at frequencies below and above $250 \mathrm{~Hz}$. Thresholds at 25 and $250 \mathrm{~Hz}$ are essentially the same in the adult and child groups. Further measurements must be made to determine the shape of the curve at frequencies below $25 \mathrm{~Hz}$. The consistency between these results and the filter analog model of the Pacinian corpuscle should be tested further by measurements of an elderly group of subjects.

\section{REFERENCES}

BÉkÉsy, G. von. Über die Vibrationsempfindung. Akustica Zeitschrift, 1939, 4, 316-334.

Cauna, N. The effects of aging on the receptor organs of the human dermis. In W. Montagna (Ed.), Advances in biology of skin: Aging (Vol. 6). New York: Pergamon, 1965. Pp. 63-96.
CRAIG, J. C. Vibrotactile loudness addition. Perception \& Psychophysics, 1966, 1, 185-190.

CraIG, J. C. Vibrotactile spatial summation. Perception \& Psychophysics, 1968, 4, 351-354.

GescheIDER, G. A. Evidence in support of the duplex theory of mechanoreception. Sensory Processes, 1976, 1, 68-76.

HubBARD, S. J. A study of rapid mechanical events in a mechanoreceptor. Journal of Physiology (London), 1958, 41, 199-218.

Loewenstein, W. R., \& Mendelson, M. Components of receptor adaptation in a Pacinian corpuscle. Journal of Physiology (London), 1965, 177, 377-397.

Loewenstein, W. R., \& RathKamp, R. The sites for mechano-electric conversion in a Pacinian corpuscle. Journal of General Physiology, 1958, 41, 1245-1265.

Loewenstein, W. R., \& SKalak, R. Mechanical transmission in a Pacinian corpuscle. Journal of Physiology (London), $1966,182,346-378$.

SherRICK, C. E., JR. Variables affecting sensitivity of the human skin to mechanical vibration. Journal of Experimental Psychology, 1953, 45, 273-282.

Stevens, S. S. Tactile vibration: Dynamics of sensory intensity. Journal of Experimental Psychology, 1959, 57, 210-218.

Stevens, S. S. Tactile vibration: Change of exponent with frequency. Perception \& Psychophysics, 1968, 3, 223-228.

Talbot, W. H., Darian-Smith, I., Kornhuber, H. H., \& Mountcastle, V. B. The sense of flutter-vibration: Comparison of the human capacity with response patterns of mechanoreceptive afferents in the monkey hand. Journal of Neurophysiology, 1968, 31, 301-334.

VERRILLO, R. T. Investigation of some parameters of the cutaneous threshold of vibration. Journal of the Acoustical Society of America, 1962, 34, 1768-1773.

VerRILLO, R. T. Effect of contactor area on the vibrotactile threshold. Journal of the Acoustical Society of America, 1963, 35, 1962-1966.

Verrillo, R. T. Temporal summation in vibrotactile sensitivity. Journal of the Acoustical Society of America, $1965,37,843-846$.

Verrillo, R. T. Effect of spatial parameters on the vibrotactile threshold. Journal of Experimental Psychology, 1966, 71, 570-575. (a)

VERrillo, R. T. Vibrotactile thresholds for hairy skin. Journal of Experimental Psychology, 1966, 72, 47-50. (b)

Verrillo, R. T. Specificity of a cutaneous receptor. Perception \& Psychophysics, 1966, 1, 149-153. (c)

Verrillo, R. T. Vibrotactile sensitivity and the frequency response of the Pacinian corpuscle. Psychonomic Science, $1966,4,135-136$. (d)

VerRILlo, R. T. A duplex mechanism of mechanoreception. In D. Kenshalo (Ed.), The skin senses. Springfield, Ill: Charles C Thomas, 1968. Pp. 139-159.

Verrillo, R. T. Subjective magnitude functions for vibrotaction. IEEE Transactions on Man-Machine Systems, 1970, MMS-11, 19-24.

VERRILLO, R. T. Effect of rise time on vibrotactile thresholds. Psychonomic Science, 1971, 25, 199-200: (a)

Verrillo, R. T. Vibrotactile thresholds measured at the finger. Perception \& Psychophysics, 1971, 9, 329-330. (b)

Verrillo, R. T., Fraioli, A. J., \& Smith, R. L. Sensation magnitude of vibrotactile stimuli. Perception \& Psychophysics, 1969, 6, 366-372.

(Received for publication October 6, 1976.) 